Cite this: RSC Adv., 2014, 4, 2515

Received 30th April 2013

Accepted 1st November 2013

DOI: $10.1039 / \mathrm{c} 3 \mathrm{ra} 42131 \mathrm{~g}$

www.rsc.org/advances

\section{Development of selective, ultra-fast multiple co-sensitization to control dye loading in dye-sensitized solar cells $\dagger$}

\author{
Peter J. Holliman, ${ }^{\star a}$ Kareem J. Al-Salihi, ${ }^{a}$ Arthur Connell, ${ }^{a}$ Matthew L. Davies, ${ }^{a}$ \\ Eurig W. Jones ${ }^{a}$ and David A. Worsley ${ }^{b}$
}

\begin{abstract}
Enhancing the spectral response of dye-sensitized solar cells (DSC) is essential to increasing device efficiency and a key approach to achieve this is co-sensitization (i.e. the use of multiple dyes to absorb light from different parts of the solar spectrum). However, precise control of dye loading within DSC mesoporous metal oxide photo-anodes is non-trivial especially for very rapid processing (minutes). This is further complicated by dyes having very different partition $\left(K_{d}\right)$ and molar extinction $(\varepsilon)$ coefficients which strongly influence dye uptake and spectral response, respectively. Here, we present a highly versatile, ultra-fast (ca. $5 \mathrm{~min}$ ) desorption and re-dyeing method for dye-sensitized solar cells which can be used to precisely control dye loading in photo-electrode films. This method has been successfully applied to re-dye, partially desorb and re-dye and selectively desorb and re-dye photo-electrodes using examples of a Ru-bipy dye (N719) and also organic dyes (SQ1 and D149) giving $\eta$ up to 8.1\% for a device containing the organic dye D149 and re-dyed with the Ru dye N719. The paper also illustrates how this method can be used to rapidly screen large numbers of dyes (and/or dye combinations) and also illustrates how it can also be used to selectively study dye loading.
\end{abstract}

In 1991, O'Regan and Grätzel described a breakthrough increase in dye-sensitized solar cell (DSC) efficiency by sensitizing nanoparticulate $\mathrm{TiO}_{2}$ with Ru-bipyridyl dye. ${ }^{1}$ Since this, many new dyes have been reported ${ }^{2}$ with excellent spectral response from $450-600 \mathrm{~nm}$ where solar intensity is highest leading to $\eta>12 \%{ }^{3}$ However, there remains great scope to increase DSC efficiency and spectral response with two broad approaches being possible; either pan-chromatization using one dye with a wide spectral response or co-sensitization using multiple dyes to absorb at different wavelengths. Panchromatic dyes include Ru-terpyridyl "black dye" $(\eta=10 \%)^{4}$ and the squaraine (JK-216, $\eta=6.3 \%$ ) dye ${ }^{5}$ although broader absorption can limit $V_{\mathrm{oc}}$ because, in this approach, the LUMO must drop to ensure a long wavelength absorption onset and/or $\varepsilon$ because it is difficult to design a dye with consistently high $\varepsilon$ across the entire solar spectrum. By comparison, co-sensitization uses more than one dye so HOMO-LUMO energy levels can be off-set and dye loading can be used to help manage $\varepsilon$ and spectral response. Previous co-sensitization examples include a multilayer approach sensitizing $\mathrm{TiO}_{2}$ with one dye, then depositing

${ }^{a}$ School of Chemistry, Bangor University, Gwynedd LL57 2UW, UK. E-mail: p.j. holliman@bangor.ac.uk; Fax: +44 (0)1248 370528; Tel: +44 (0)1248 382375

${ }^{b}$ SPECIFIC, College of Engineering Swansea University, Baglan Bay Innovation and Knowledge Centre, Port Talbot SA12 7AZ, UK

$\dagger$ Electronic supplementary information (ESI) available. See DOI: $10.1039 / \mathrm{c} 3 \mathrm{ra} 42131 \mathrm{~g}$ an $\mathrm{Al}_{2} \mathrm{O}_{3}$ layer and then a second dye ${ }^{6}$ leading to $\eta=8.65 \%$ for $\mathrm{JK} 2, \mathrm{Al}_{2} \mathrm{O}_{3}$ and then SQ1. ${ }^{7}$ Other approaches have used supercritical fluids, $^{8}$ specialist photo-electrodes ${ }^{9,10}$ or slow dyeing procedures $^{11-15}$ to control dye uptake leading to the highest reported DSC efficiency $(\eta>12 \%)$ using a Zn-porphyrin and a triphenylamine dye with a Co complex as the redox couple. ${ }^{3}$

Current limitations on the co-sensitization approach include the dyeing times (i.e. hours) and controlling the dyeing process (e.g. dye loading and surface organisation). In this context, we recently reported ultra-fast co-sensitization (5 min) using N719 and SQ1 giving $\eta=7.9 \%$ (ref. 16) and the first example of ultrafast tri-sensitization ${ }^{17}$ by pumping dye solution through presealed devices to overcome the mass transfer issues of passive dyeing. Thus, ultra-fast sensitization is controlled by the rate of dye adsorption which is influenced by dye partition coefficients (solvated $v s$. adsorbed). However, these partition coefficients are fixed for each dye-solvent-metal oxide system which limits the control of dye loading in what is a competitive sorption process. Thus, increasing dye loading for a single dye involves simply dyeing for longer and rinsing away any excess. However, for multiple dyeing, this approach is only possible if all the dyes being used have identical partition coefficients which is extremely unlikely. Hence, dye uptake from a multiple dye solution is dominated by the highest partition coefficient dye.

It is well known that dye loading can be measured by dye desorption typically using $\mathrm{NaOH}$ to de-esterify chemisorbed dyes from the $\mathrm{TiO}_{2}$ surface. In general, desorption processes 
have been much less studied to date with Park et al. positioning dyes using gelled alkali ${ }^{18}$ and O'Regan et al. using dilute alkali to desorb dyes to study recombination processes. ${ }^{19}$

We report here new, ultra-fast co-sensitization procedures which overcome the limitations caused by varying $\varepsilon$ and $K_{\mathrm{d}}$ between different dyes and which enable much greater control of dye loading even at processing times of minutes. This has been achieved through total, partial and/or selective dye desorption and re-dyeing of selected metal complex and organic dyes and replacement with others. This paper also reports links between $J_{\mathrm{sc}}$, spectral response and device efficiency for multiply co-sensitized DSC devices including the first ever examples of ultra-selective, ultra-fast desorption of tri-sensitized DSC photoelectrodes. The data show that these approaches to desorption and re-dyeing are entirely tunable to different dyes and can produce bespoke DSC devices where the colour, spectral response and transparency etc. can be precisely controlled in a matter of minutes.

\section{Results and discussion}

\section{Ultra-fast desorption by various alkali solutions}

Different alkaline solutions have been tested for the ultra-fast desorption of N719 dye which had been adsorbed using ultrafast pump dyeing ( $1 \mathrm{ml}, 1 \mathrm{mM}$ N719 in $\left.1: 1 \mathrm{CH}_{3} \mathrm{CN}:{ }^{t} \mathrm{BuOH}\right)$. A device was dyed, desorbed and then re-dyed after each desorption and IV data were measured at each stage (Table 1). The alkalis were chosen because they have similar $\mathrm{p} K_{\mathrm{b}}$ values with only a variance in the cation with the exception of tris(hydroxymethyl)ethylamine or THMA which is a weaker base $\left(\mathrm{p} K_{\mathrm{b}}=8.0\right)$.

The IV data in Table 1 show that, for the dyed devices, $J_{\mathrm{sc}}$ varies from $11.04 \mathrm{~mA} \mathrm{~cm}^{-2}$ for the initial N719 dyeing up to $13.26 \mathrm{~mA} \mathrm{~cm}{ }^{-2}$ after the fifth cycle of dyeing. This increase might either be due to the changing cations or to the repeated $\mathrm{pH}$ cycling from high to low which could increase the number of available dye sorption sites presumably by increasing surface $\mathrm{OH}$ groups on the $\mathrm{TiO}_{2}$. Dyeing and desorbing an electrode

Table 1 I-V data for (P25) $\mathrm{TiO}_{2}$ DSC dyed with N719, then desorbed with different alkaline solutions and re-dyed with N719

\begin{tabular}{|c|c|c|c|c|}
\hline Device & $\eta / \%$ & $V_{\mathrm{oc}} / \mathrm{V}$ & $\begin{array}{l}J_{\mathrm{sc}} / \\
\mathrm{mA} \mathrm{cm}{ }^{-2}\end{array}$ & FF \\
\hline Dyed with N719 & 4.9 & 0.70 & 11.04 & 0.64 \\
\hline Desorbed by $\mathrm{KOH}(-0.3)^{b}$ & 0.3 & 0.58 & 0.74 & 0.55 \\
\hline Re-dyed with N719 & 5.8 & 0.75 & 12.18 & 0.63 \\
\hline Desorbed by $\mathrm{NaOH}(0.5)$ & 0.3 & 0.57 & 0.80 & 0.58 \\
\hline Re-dyed with N719 & 5.3 & 0.72 & 12.21 & 0.61 \\
\hline Desorbed by LiOH (0.2) & 0.2 & 0.53 & 0.81 & 0.48 \\
\hline Re-dyed with N719 & 5.7 & 0.72 & 12.51 & 0.63 \\
\hline Desorbed by $\mathrm{Bu}_{4} \mathrm{NOH}(0.3)$ & 0.3 & 0.56 & 0.82 & 0.60 \\
\hline Re-dyed with N719 & 5.9 & 0.73 & 13.14 & 0.61 \\
\hline Desorbed by THMA ${ }^{a}(8.0)$ & 0.3 & 0.57 & 0.99 & 0.58 \\
\hline Re-dyed with N719 & 6.0 & 0.73 & 13.26 & 0.62 \\
\hline
\end{tabular}

${ }^{a}$ THMA $=$ tris(hydroxymethyl)ethylamine. ${ }^{b} \mathrm{p} K_{\mathrm{b}}$ values are shown in parentheses. using only $\mathrm{Bu}_{4} \mathrm{NOH}$ also shows an increase in $\eta$ (from $4.6 \%$ to $5.0 \%$ ) and increased $\mathrm{N} 719$ loading from 156 to $174 \mu \mathrm{g} \mathrm{cm}$ suggesting changes in the dyeing sites outweigh any cation effects. By comparison, Table 1 also shows only a slight increase in $V_{\text {oc }}$ from 0.70 to $0.73 \mathrm{~V}$ and the FF remains essentially the same (0.64-0.62).

The desorbed devices all show similar and much lower $J_{\mathrm{sc}}$ (0.74-0.99 $\left.\mathrm{mA} \mathrm{cm}^{-2}\right), V_{\text {oc }}(0.58-0.57 \mathrm{~V})$ and $\mathrm{FF}$ (0.55-0.58) in line with complete dye desorption (dye loading was ca. $162 \mu \mathrm{g}$ N719 $\mathrm{cm}^{-2}$ ). These data show a cycle of highs and lows of device efficiency corresponding to dyed and desorbed devices which show an increase in device performance from the first $(\eta=$ $4.9 \%)$ to the fifth cycle of dyeing $(\eta=6.0 \%)$ in line with $J_{\mathrm{sc}}$. Corresponding images (ESI Fig. S1 $\dagger$ ) confirm the presence and absence of adsorbed dye during each dyeing, desorption and redyeing cycle. These data confirm that it is possible to ultra-fast dye, desorb and re-dye $\mathrm{TiO}_{2}$ photo-electrodes with N719 using a range of different alkaline solutions without apparently damaging any of the exposed device components. However, further studies show that whilst alkali metal hydroxides (e.g. $\mathrm{NaOH}$ or $\mathrm{KOH}$ ) desorb $\mathrm{Ru}$ (bipy) complexes at room temperature that the removal of organic dyes such as SQ1 requires the dismantling of the device by re-heating the Surlyn gasket and removing the counter electrode followed by heating at $\geq 40{ }^{\circ} \mathrm{C}$ for $30 \mathrm{~min}$ which causes irreversible damage to device components. ${ }^{20}$ By comparison, $\mathrm{Bu}_{4} \mathrm{NOH}$ removes all dyes at room temperature without damaging device components and hence this base was chosen for more detailed studies.

\section{Studies of ultra-fast dye desorption using $\mathrm{Bu}_{4} \mathrm{NOH}$}

Initially, the effects of $\mathrm{Bu}_{4} \mathrm{NOH}$ concentration (Table 2) and volume (Fig. 1) were trialled to study ultra-fast partial dye desorption and re-dyeing. Initially, a constant volume of $100 \mu \mathrm{l}$ of $\mathrm{Bu}_{4} \mathrm{NOH}$ was used (Table 1). Given that a $25 \mu \mathrm{m}$ Surlyn gasket was used and the photo-electrode area was $c a .1 \mathrm{~cm}^{2}(0.5 \times$ $2.0 \mathrm{~cm}^{2}$ ) this suggests the device cavity was $c a .20 \mu \mathrm{l}$ which means that the alkali would replenish this volume five times during the desorption cycle. The data show that this device gives $\eta=4.7-5.0 \%$ when fully dyed and that $20-40 \mathrm{mM} \mathrm{Bu}_{4} \mathrm{NOH}$ is sufficient to desorb all the N719. By comparison, $10 \mathrm{mM}$ $\mathrm{Bu}_{4} \mathrm{NOH}$ results in partial dye desorption giving a $c a .4 / 5^{\text {th }}$ drop in the $J_{\mathrm{sc}}$ value $\left(2.2 \mathrm{~mA} \mathrm{~cm}^{-2}\right.$ versus $\left.11.3 \mathrm{~mA} \mathrm{~cm}^{-2}\right)$. Dropping

Table 2 I-V data for (P25) DSC device dyed with N719 (1 ml, $2.8 \mathrm{mM})$ and desorbed with $100 \mu \mathrm{l} \mathrm{Bu}{ }_{4} \mathrm{NOH}(4 \mathrm{mM}-40 \mathrm{mM})$

\begin{tabular}{lllcl}
\hline Device & $\eta / \%$ & $V_{\mathrm{oc}} / \mathrm{V}$ & $\begin{array}{l}J_{\mathrm{sc}} / \\
\mathrm{mA} \mathrm{cm}\end{array}$ & $\mathrm{FF}$ \\
\hline Dyed with N719 & 4.9 & 0.80 & 12.05 & 0.51 \\
Desorbed by 40 mM & 0.3 & 0.59 & 0.81 & 0.68 \\
Re-dyed with N719 & 5.0 & 0.77 & 11.87 & 0.55 \\
Desorbed by 20 mM & 0.4 & 0.6 & 0.85 & 0.69 \\
Re-dyed with N719 & 4.9 & 0.77 & 11.30 & 0.57 \\
Desorbed by 10 mM & 0.9 & 0.64 & 2.21 & 0.64 \\
Re-dyed with N719 & 4.7 & 0.76 & 11.26 & 0.55 \\
Desorbed by 4 mM & 4.2 & 0.76 & 10.02 & 0.56 \\
Re-dyed with N719 & 4.9 & 0.77 & 10.35 & 0.61
\end{tabular}




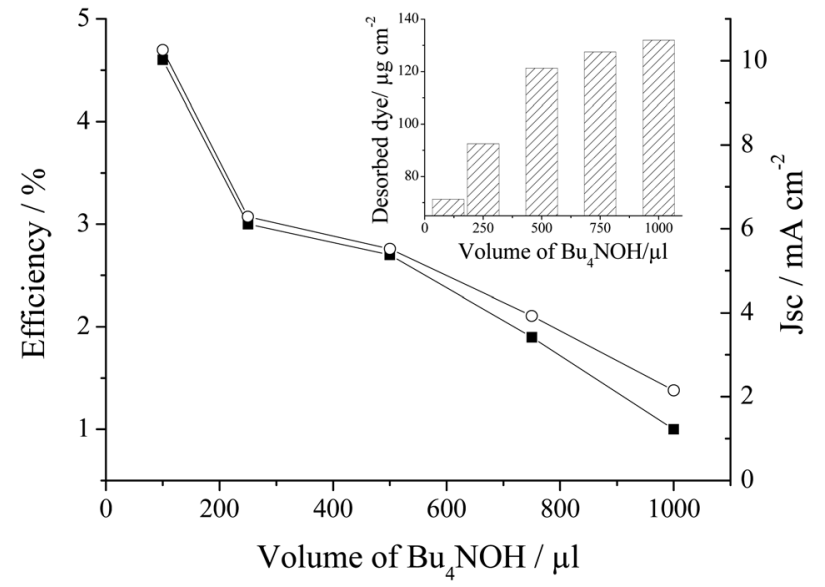

Fig. $1 \eta, \mathrm{J}_{\mathrm{sc}}$ and dye loading for a $\mathrm{TiO}_{2}$ device fast dyed with N719 $(1 \mathrm{ml}, 2.8 \mathrm{mM})$ and desorbed with varying volumes of $4 \mathrm{mM} \mathrm{Bu} \mathrm{HOH}_{4} \mathrm{NO}$. Efficiency shown as black squares and $J_{\text {sc }}$ as open circles. Inset shows dye loading versus volume of $\mathrm{Bu}_{4} \mathrm{NOH}$.

this concentration to $4 \mathrm{mM}$ results in only a small drop in $J_{\mathrm{sc}}$ (10 $\mathrm{mA} \mathrm{cm} \mathrm{cm}^{-2}$ versus $11.3 \mathrm{~mA} \mathrm{~cm}^{-2}$ ) implying partial dye desorption is possible.

The effects of $\mathrm{Bu}_{4} \mathrm{NOH}$ volume on N719 desorption have been studied between 1000 and $100 \mu \mathrm{l}$ using a $4 \mathrm{mM}$ $\mathrm{Bu}_{4} \mathrm{NOH}$ solution. Fig. 1 shows that higher volumes desorb more dye which reduces both $J_{\mathrm{sc}}$ and $\eta$ in parallel as expected. However, the relationships between $\mathrm{Bu}_{4} \mathrm{NOH}$ volume, the loading of dye desorbed and the $\eta / J_{\text {sc }}$ are not linear. Thus, 500-1000 $\mu \mathrm{l}$ of $\mathrm{Bu}_{4} \mathrm{NOH}$ desorbs between 121 and $132 \mu \mathrm{g}$ $\mathrm{cm}^{-2}$ which drops to $\mathrm{ca}$. half the initial dye desorption $(71 \mu \mathrm{g}$ $\mathrm{cm}^{-2}$ ) for $100 \mu \mathrm{l}$ of alkali. By comparison, $J_{\mathrm{sc}}$ and $\eta$ did increase in step-wise increments as the alkali volume drops. This suggests that the link between dye loading and $J_{\mathrm{sc}}$ when dye is desorbed from a pre-dyed device is more complicated than a simple linear relationship. Thus, it is known that the uppermost portion of a mesoporous film dyes more rapidly than the rest of the film (as this comes into contact with the dye solution first) and that ultra-fast dyeing overcomes the limitations of mass transport through such films to speed up complete dyeing of the film. ${ }^{16}$ In the same way, ultra-fast desorption is expected to overcome mass transport limitations of alkali solution passing through the film. However, changing the volume of the solution passing through the film must also changes the residence time (for a similar pumping rate) and this would be expected to have a greater impact on desorption rates than a simple linear proportionality. Overall, these data show that it is possible to partially remove adsorbed dye from a photo-electrode in a controlled manner by varying the volume and/or concentration of the dye solution. These data also suggest that some dye can be removed with relatively less impact on device performance. This is important because this should make dye sites available within the $\mathrm{TiO}_{2}$ for a different dye which, if it can harvest photons which are not absorbed by the first dye (due to poor spectral response at a particular wavelength) then this could potentially enhance overall device light harvesting.

\section{Ultra-fast total desorption and re-dyeing using different dyes}

Complete dye desorption and re-dyeing was then studied using a range of different dyes. In the first example, Device A1 was pump dyed with $1 \mathrm{ml}$ of the Ru-bipy dye N719 giving $\eta$ of $6.2 \%$ which is typical for a $1 \mathrm{~cm}^{2} \mathrm{TiO}_{2}$ photo-electrode (Table 3). The N719 was then rapidly and completely desorbed by pumping $40 \mathrm{mM} \mathrm{Bu}{ }_{4} \mathrm{NOH}_{(\mathrm{aq})}$ through the device cavity. Complete dye removal was confirmed visually because the photo-electrode became white (Fig. 2) and an N719-coloured desorption solution was produced which was subsequently confirmed by UV-vis spectroscopy. In line with dye desorption, after re-filling with $\mathrm{I}_{3}{ }^{-} / \mathrm{I}^{-}$electrolyte, the device efficiency had dropped to $\eta=0.3 \%$. After electrolyte removal and device cavity rinsing with $100 \mu \mathrm{l}$ of ethanol, the device was re-dyed with N719 and the resulting Device A2 showed identical efficiency to the first dyeing (Device A1) with a small increase in $J_{\mathrm{sc}}$ which might suggest a slightly higher dye loading but also a $20 \mathrm{mV}$ reduction in $V_{\mathrm{oc}}$. The slight

Table $3 \quad I-V$ data for completely desorbed and re-dyed DSL18NR-T $\mathrm{TiO}_{2}$ devices

\begin{tabular}{|c|c|c|c|c|c|}
\hline & & $\eta / \%$ & $V_{\mathrm{oc}} / \mathrm{V}$ & $\begin{array}{c}J_{\mathrm{sc}} / \mathrm{mA} \\
\mathrm{cm}^{-2}\end{array}$ & $\mathrm{FF}$ \\
\hline A1 & Dye N719 & 6.2 & 0.72 & 13.45 & 0.64 \\
\hline A2 & Re-dyed with N719 & 6.2 & 0.70 & 14.16 & 0.63 \\
\hline B1 & Dye SQ1 & 3.1 & 0.59 & 8.21 & 0.64 \\
\hline B2 & Re-dyed with SQ1 & 3.2 & 0.61 & 8.42 & 0.62 \\
\hline C1 & Dye SQ1 & 3.1 & 0.59 & 8.31 & 0.62 \\
\hline $\mathrm{C} 2$ & Re-dyed with N719 & 6.3 & 0.73 & 13.47 & 0.64 \\
\hline D1 & Dye N719 & 6.0 & 0.71 & 13.22 & 0.64 \\
\hline D2 & Re-dyed with SQ1 & 2.8 & 0.61 & 7.27 & 0.63 \\
\hline E1 & Dye N719:SQ1 & 7.2 & 0.74 & 15.99 & 0.60 \\
\hline E2 & Re-dyed - N719:SQ1 & 6.7 & 0.73 & 14.52 & 0.63 \\
\hline
\end{tabular}

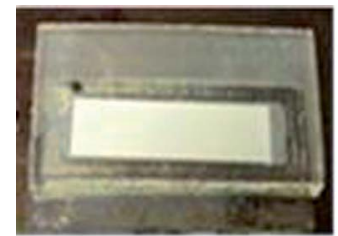

(a)

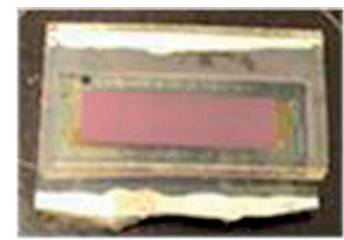

(b)

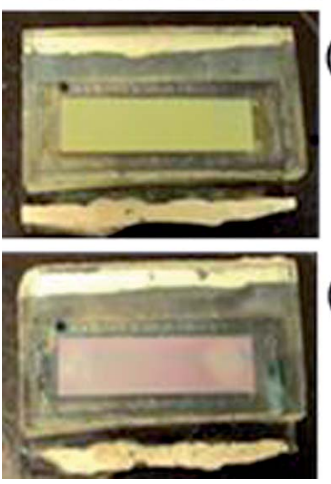

(c)

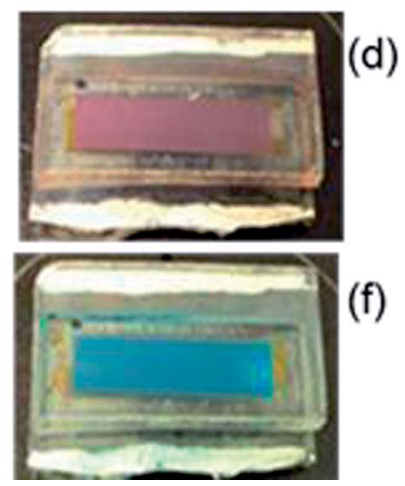

Fig. 2 DSC devices showing colour changes (a) before dyeing, (b) after N719 dyeing, (c) after N719 desorption - the yellow colour is due to $\mathrm{I}_{3}{ }^{-} / \mathrm{I}^{-}$electrolyte, (d) after N719 re-dyeing, (e) after partial desorption of N719 and (f) after re-dyeing with SQ1. 

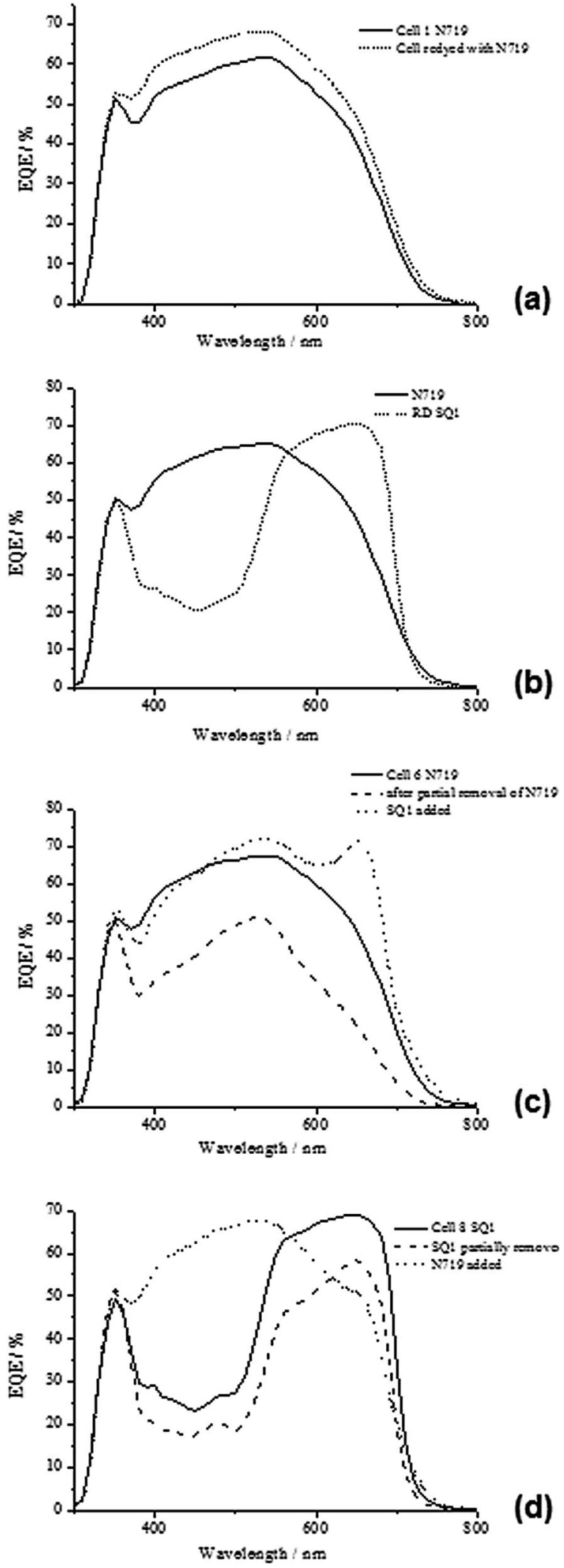

Fig. 3 EQE data for dyed, desorbed and re-dyed DSC devices; (a) dyed and re-dyed N719, (b) dyed with N719, re-dyed with SQ1, (c) dyed with N719, partially removed and re-dyed with SQ1 and (d) dyed with SQ1, partial SQ1 removal and re-dyed with N719. increase in $J_{\mathrm{sc}}$ was further confirmed by the EQE data (Fig. 3) of the re-dyed device which shows a slightly higher $\mathrm{EQE}_{\max }$ at $c a$. $560 \mathrm{~nm}(68 \%)$ compared to the initial dyeing (62\%). This confirms that, when $\mathrm{BuN}_{4} \mathrm{OH}$ base is used for dye desorption, rapid and complete dye removal is possible at room temperature with no degradation of the metal oxide surface or any of the device components (conducting layers, platinized counter electrode) which are all also exposed to the desorption solution.

Device B1 was dyed with $300 \mu \mathrm{l}$ of ethanolic SQ1 solution; the lower volume of solution reflecting the much higher $\varepsilon$ of SQ1 compared to N719 (ca. 158500 (ref. 21) vs. ca. $14000 \mathrm{M}^{-1} \mathrm{~cm}^{-1}$ (ref. 22)). The data (Table 3) show a similar pattern to N719 with the initial SQ1 dyeing (Device B1) giving $\eta=3.1 \%$ which dropped to $0.3 \%$ after dye desorption with $40 \mathrm{mM} \mathrm{Bu}_{4} \mathrm{NOH}$. Again the desorbed photo-electrode became white and the desorbed dye solution became SQ1-coloured (blue) which was confirmed by UV-visible spectroscopy. Re-dyeing with SQ1 again gave almost identical device performance (Device B2) to the initial SQ1 dyeing although very slight increases in $V_{\mathrm{oc}}(20 \mathrm{mV})$ and $J_{\mathrm{sc}}\left(0.2 \mathrm{~mA} \mathrm{~cm}{ }^{-2}\right)$ were observed which again suggests that no degradation of the device components had taken place. Again the $\mathrm{EQE}_{\max }$ of the re-dyed device at $c a .650 \mathrm{~nm}$ showed a slight increase compared to the initial dyeing although this is balanced by a small decrease in EQE between 400 and $500 \mathrm{~nm}$ where the dye is less efficient which may explain why the increase in $J_{\mathrm{sc}}$ increase is small (see ESI $\dagger$ ).

Having established that one dye can be removed and replaced without any loss of performance, a study was carried out to see if the same photo-electrode could be desorbed and dyed with different dyes. Thus, Device C1 was first dyed with $300 \mu \mathrm{l}$ of SQ1 solution showing $\eta$ of $3.1 \%$ which is in line with the data for Device B1. After removal of this dye, the same device was dyed with $1 \mathrm{ml}$ of N719 and the efficiency increased to 6.3\% (Device C2); reflecting an increase in $J_{\mathrm{sc}}$ and $V_{\mathrm{oc}}$ for $\mathrm{N} 719$ versus SQ1. The data for Device C2 are also in line with the data for Device A1 with almost identical $J_{\mathrm{sc}}$ and $V_{\mathrm{oc}}$ again support the idea that no change had occurred to the device components during desorption and re-dyeing. To test whether the order of dyeing affects the process, Device D1 was first pump dyed with N719 giving $\eta$ of $6.0 \%$ which is comparable to the other N719 devices. However, Device D2 shows a drop in $\eta$ to $2.8 \%$ after N719 desorption and re-dyeing with SQ1 which was due to lower $J_{\text {sc }}$ and $V_{\text {oc }}$ typical for SQ1 vs. N719. The EQE data for Device D1 (Fig. 3b) confirms the differing EQE responses for the different dyes with an initial broad spectral response $\left(\mathrm{EQE}_{\max }=560 \mathrm{~nm}\right)$ typical of N719 followed by the typical response for SQ1 $\left(\mathrm{EQE}_{\max }=640 \mathrm{~nm}\right)$. These data confirm that the N719 dye is desorbed and that only SQ1 dye is responsible for light harvesting in the re-dyed device.

Having established that it is possible to change dyes within the same device, a study was carried out to test if a co-sensitized device can be desorbed and re-dyed. To do this, Device E1 was dyed with $1 \mathrm{ml}$ of a mixed dye solution containing $2.8 \mathrm{mM} \mathrm{N719}$ and $0.17 \mathrm{mM}$ SQ1 giving $\eta=7.2 \%$ (Table 3 ) which is greater than the efficiency for N719 alone (Device A1) mainly due to an increase in $J_{\mathrm{sc}}$ as might be expected for an increased spectral response from co-sensitization. When the dyes are desorbed 
using $40 \mathrm{mM} \mathrm{Bu}_{4} \mathrm{NOH}$, all the dyes are fully removed as evidenced by a change in colour of the photo-electrode to white whilst UV-visible spectroscopy confirms an initial dye loading of 202.0 and $1.0 \mu \mathrm{g} \mathrm{cm}^{-2}$ for N719 and SQ1, respectively.

After addition of electrolyte, the device efficiency drops $(\eta=$ $0.3 \%$ ) in line with complete dye removal. After washing and redyeing with $1 \mathrm{ml}$ of the same N719:SQ1 dye solution, the device efficiency returns to $\eta=6.7 \%$ (Device E2); the drop from Device $\mathrm{E} 1$ being due to a drop in $J_{\mathrm{sc}}$ is reflected in the slightly lower EQE (see ESI $\dagger$ ) although the signal for SQ1 is clearer for the re-dyed device presumably due to the weaker response of N719. Further dye desorption of this device actually shows a higher N719 loading $\left(240 \mu \mathrm{g} \mathrm{cm}^{-2}\right)$ but a similar SQ1 loading. This might possibly suggest some slight N719 dye aggregation causing reduced light harvesting. Whilst the data in Table 3 confirm that dyeing, desorption and re-dyeing can be successfully achieved for single and mixed dye solutions and the consistent fill factors suggest that device components are not damaged by careful choice of desorption and rinsing solutions even over many cycles (data not shown), Device E suggests that it can be more difficult to precisely control dye loadings from mixed dye solutions.

\section{Partial dye desorption and re-dyeing}

To further study the ability to accurately control dye loading in multiply dyed devices, partial dye desorption and re-dyeing with a different dye was first studied. To do this, Device F1 was first dyed with $1 \mathrm{ml}$ of N719 solution giving a typical efficiency for this dye ( $\eta=6.5 \%$, Table 4$)$. Then N719 desorption was studied using a small volume $(100 \mu \mathrm{l})$ of a low concentration $(1 \mathrm{mM})$ of $\mathrm{Bu}_{4} \mathrm{NOH}_{(\mathrm{aq})}$. This resulted in partial N719 removal such that UVvis spectroscopy showed that $80 \mu \mathrm{g} \mathrm{cm}^{-2}$ of N719 was desorbed and $J_{\mathrm{sc}}$ dropped from 13.19 to $12.29 \mathrm{~mA} \mathrm{~cm}^{-2}$ (Device F2). The EQE response after partial removal of N719 also showed a reduction in the $\mathrm{EQE}_{\max }$ at $c a .550 \mathrm{~nm}$ from $c a$. $65 \%$ down to just under $50 \%$. The $V_{\text {oc }}$ for Device F2 also dropped $50 \mathrm{mV}$ to $0.69 \mathrm{~V}$ which may reflect increased back reaction taking place at vacated dye sites on the $\mathrm{TiO}_{2}$ surface. It is interesting to note that again the drop in $J_{\mathrm{sc}}$ and $\eta$ are less than might be expected for a linear relationship between dye loading and $\eta$. This is an important result for several reasons. Firstly, it implies that there are some dye sites within the electrode which do not operate as efficiently as others. In turn, this implies that these vacated sites could be sensitized with a different dye which might absorb at a

Table $4 \quad I-V$ data for (DSL18NR-T) DSC devices showing partial desorption and selective dyeing

\begin{tabular}{llllll}
\hline & & & & \multicolumn{3}{c}{$J_{\mathrm{sc}} / \mathrm{mA}$} & \\
Device & & $\eta / \%$ & $V_{\mathrm{oc}} / \mathrm{V}$ & $\mathrm{cm}^{-2}$ & $\mathrm{FF}$ \\
\hline F1 & N719 & 6.5 & 0.74 & 13.19 & 0.67 \\
F2 & Partial desorption & 5.2 & 0.69 & 12.29 & 0.62 \\
F3 & SQ1 added & 5.6 & 0.67 & 13.87 & 0.60 \\
G1 & Dyed with SQ1 & 2.8 & 0.60 & 8.37 & 0.65 \\
G2 & Partial SQ1 removal & 2.2 & 0.56 & 6.29 & 0.63 \\
G3 & N719 added & 6.5 & 0.60 & 15.02 & 0.72
\end{tabular}

different part of the solar spectrum and so increase the overall photo-current. In the example here (Device F3, Table 4) this is exactly what happens when the device is re-dyed with SQ1 with a small increase in $J_{\text {sc }}$ to $13.87 \mathrm{~mA} \mathrm{~cm}{ }^{-2}$ although the $V_{\text {oc }}$ actually drops another $20 \mathrm{mV}$ to $0.67 \mathrm{~V}$ which reflects the addition of SQ1 which has a lower $V_{\mathrm{oc}}$ than $\mathrm{N} 719$ (see e.g. Device B1 in Table 3). This limits $\eta$ to $5.6 \%$ for Device F3. EQE confirms the additional light harvesting of SQ1 and confirms that both dyes are contributing to the spectral response of this device (Fig. 3c). Interestingly, complete dye desorption from Device F3 gave dye loadings of 159 and $13 \mu \mathrm{g} \mathrm{cm}^{-2}$ for N719 and SQ1, respectively. Thus, Device F3 has a higher SQ1 loading than Device E which, by comparison, was co-sensitized from a mixed N719:SQ1 dye solution under conditions of directly competitive adsorption between these two dyes. The EQE signal for SQ1 is much clearer in Device F3 than in Device E in line with the higher SQ1 loading.

Looking at the dyeing, partial desorption and re-dyeing cycle for Device F, although it is difficult to conclusively prove the following effect, it is possible that the small volume of alkali used to partially desorb the N719 might cause preferential desorption of dye in the upper part of the photo-electrode. This might explain the non-linear relationship between dye loading and $J_{\mathrm{sc}}$ because presumably the most effective N719 should located closest to the direction of illumination. In these examples, which have used normal illumination, the dye closest to the working electrode should be the most effective. Hence, this might suggest that ultra-fast selective positioning of dyes within the photo-electrode is possible which is an important issue for scaling up the manufacture of these devices as previous reports have of dye positioning have required processing times of hours. ${ }^{8}$

Devices G1-G3 have been dyed in the opposite order to study how this affects device performance. Hence, Device G1 was first dyed with $500 \mu \mathrm{l}$ of $0.70 \mathrm{mM}$ SQ1 (with $5 \mathrm{mM} \mathrm{CDCA}$ ) giving $\eta=$ $2.8 \%$. SQ1 was then partially removed using $10 \mu \mathrm{l}$ of $1 \mathrm{mM}$ $\mathrm{BuN}_{4} \mathrm{OH}$ giving $\eta=2.2 \%$ mainly due to a drop in $J_{\mathrm{sc}}$ in line with partial dye removal (Device G2). After rinsing the device cavity, the photo-electrode was re-dyed with $1 \mathrm{ml}$ of N719 solution resulting in a large increase in $J_{\mathrm{sc}}$ from 6.29 to $15.02 \mathrm{~mA} \mathrm{~cm}^{-2}$ and an efficiency of $6.5 \%$. This $J_{\mathrm{sc}}$ value is comparable to Device E2 which was also co-sensitized with a mixture of SQ1 and N719. The changing dye loadings are reflected in the EQE data (Fig. 3d) which show that the initial dyeing gives a typical SQ1 spectral response with $\mathrm{EQE}_{\max } 68 \%$ at $c a .650 \mathrm{~nm}$ but that this response drops to just under $60 \%$ after partial dye desorption. However, re-dyeing with N719 shows a big change with the broad spectral response of N719 being apparent with $\mathrm{EQE}_{\max }$ at $550 \mathrm{~nm}$ with a drop in the SQ1 response to $c a$. $50 \%$ which is a different effect from when the dyeing takes place in the opposite order in Device F (Fig. 3c) where the SQ1 signal is at 70\% but appears narrower which may suggest less SQ1 aggregation. This would be logical because adding SQ1 into sites vacated by N719 would have to result in isolated SQ1 molecules whereas the opposite would occur if N719 is added afterwards.

The changing dye loadings were also observed in the changing colour of the photo-electrode after each dyeing step 
(see ESI $\dagger$ ). In line with the lower dye loading very little alkali solution is required to remove some of the SQ1. It is interesting though how much re-dyeing with N719 increases the photocurrent when initially it might be expected that there would be few dyeing vacant sites available. One possibility is that there might be different dyeing sites for these two dyes; one set of sites might not be available to SQ1 but remain available to N179. It is also possible that the small volume and low concentration of $\mathrm{BuN}_{4} \mathrm{OH}$ used could partially desorb the SQ1 in Device G2 preferentially from the "top" of the photo-electrode (closest to the holes in the counter electrode through which the desorption solution is pumped). This could leave relatively more vacant dye sites in this region of the photo-electrode. On this basis, re-dyeing with N719 might be expected to preferentially dye the "top" of the photo-electrode with N719. However, comparing the Devices F3 and G3, the data suggest that, for these two sensitizers, the order in which the dyes are adsorbed onto the $\mathrm{TiO}_{2}$ surface is more important than the position of the dyes within the photo-electrode. This may reflect more favourable surface organisation when SQ1 is allowed to adsorb before N719. However, the ability to selectively position dyes within a photo-electrode remains an important concept and is likely to be advantageous in a number of scenarios. For instance, where two or more dyes have vastly different partition coefficients $\left(K_{\mathrm{d}}\right)$, the dye with the larger $K_{\mathrm{d}}$ will always dominate the surface making precise control of dye loadings difficult. In addition, for multiply sensitized devices where the dye combinations used either suffer inter-dye recombination problems separating the dyes to different parts of the photo-electrode should reduce this problem.

\section{Selective dye desorption}

Having established that it is possible to partially desorb and redye DSC devices, a study of selective dye desorption was carried out to see if it is possible to multiply co-sensitize a $\mathrm{TiO}_{2}$ photoelectrode and then selectively remove different dyes. To do this, Device $\mathrm{H} 1$ was first dyed with $2 \mathrm{ml}$ of a mixed dye solution containing $0.70 \mathrm{mM}$ N719, $0.375 \mathrm{mM}$ D149 and $10 \mathrm{mM}$ CDCA giving $\eta=7.2 \%$ and a $J_{\mathrm{sc}}$ of $16.72 \mathrm{~mA} \mathrm{~cm}^{-2}$ which is significantly more than the photo-current achieved for N719 alone (e.g. Device A1). This result is interesting because both N719 and D149 absorb at similar wavelengths. However, the EQE data show that improved light harvesting can still be achieved because there is mismatch between the EQE profiles of the two dyes such that the correct dye loading of a mixture of both dyes should result in a broader EQE response than is possible for either dye on it's own (see ESI $\dagger$ ). Such an effect has previously been shown for triarylamine dyes combined with N719 (ref. 16) and also for an organic dye with a porphyrin. ${ }^{3}$ After this, the N719 dye was selectively removed using $100 \mu \mathrm{l}$ of $0.1 \mathrm{M} \mathrm{LiOH}_{(\mathrm{aq})}$ resulting in a drop in $\eta$ to $4.6 \%$ mainly due to the $J_{\text {sc }}$ dropping to $11.40 \mathrm{~mA} \mathrm{~cm}{ }^{-2}$ (Device H2). Selective N719 removal was confirmed by UV-vis spectroscopy (ESI Fig. S12†) which showed only N719 in the LiOH solution. Interestingly, when the device was re-dyed with $1 \mathrm{ml}$ of standard N719 solution, the efficiency increased to $8.1 \%$ (Device $\mathrm{H} 3$ ) which was higher than that for
Table $5 \quad I-V$ data for selectively desorbed and re-dyed (DSL18NR-T) DSC devices

\begin{tabular}{|c|c|c|c|c|c|}
\hline \multicolumn{2}{|c|}{ Device } & \multirow{2}{*}{$\frac{\eta / \%}{7.2}$} & \multirow{2}{*}{$\frac{V_{\mathrm{oc}} / \mathrm{V}}{0.69}$} & \multirow{2}{*}{$\begin{array}{c}\begin{array}{l}J_{\mathrm{sc}} / \mathrm{mA} \\
\mathrm{cm}^{-2}\end{array} \\
16.72\end{array}$} & \multirow{2}{*}{$\frac{F F}{0.69}$} \\
\hline H1 & D149:N719 & & & & \\
\hline $\mathrm{H} 2$ & Partial N719 removal & 4.6 & 0.66 & 11.40 & 0.61 \\
\hline Н3 & Re-dyed with N719 & 8.1 & 0.71 & 17.81 & 0.64 \\
\hline I1 & Dyed with N719 & 5.9 & 0.78 & 10.77 & 0.63 \\
\hline $\mathrm{I} 2$ & SQ1 added & 5.1 & 0.74 & 9.25 & 0.67 \\
\hline I3 & N719 desorbed & 0.7 & 0.61 & 1.42 & 0.68 \\
\hline I4 & Re-dyed with SQ1 & 2.3 & 0.66 & 4.47 & 0.71 \\
\hline I5 & N719 added & 5.2 & 0.73 & 9.75 & 0.66 \\
\hline $\mathrm{J} 1$ & Dyed with N719 & 5.1 & 0.81 & 11.30 & 0.56 \\
\hline $\mathrm{J} 2$ & Partial N719 removal & 3.6 & 0.63 & 10.16 & 0.57 \\
\hline J3 & D149 added & 3.8 & 0.65 & 11.82 & 0.50 \\
\hline $\mathrm{J} 4$ & Selective N719 removal & 2.9 & 0.60 & 8.27 & 0.58 \\
\hline J5 & Re-dyed with N719 & 5.9 & 0.80 & 11.70 & 0.51 \\
\hline K1 & Dyed with SQ1 & 2.3 & 0.60 & 6.39 & 0.61 \\
\hline K2 & N719 added & 4.8 & 0.68 & 13.47 & 0.53 \\
\hline K3 & D149 added & 5.5 & 0.69 & 13.36 & 0.59 \\
\hline K4 & N719 desorbed & 0.8 & 0.78 & 1.44 & 0.67 \\
\hline K5 & SQ1 desorbed & 1.3 & 0.61 & 3.72 & 0.60 \\
\hline K6 & D149 desorbed & 0.3 & 0.57 & 0.84 & 0.62 \\
\hline
\end{tabular}

the original device in this series (Device H1) mainly due to $J_{\mathrm{sc}}$ increasing to $17.8 \mathrm{~mA} \mathrm{~cm} \mathrm{~cm}^{-2}$ (Table 5). This again suggests that the method of dyeing can strongly affect device performance presumably because this influences the organisation of dyes on the $\mathrm{TiO}_{2}$ surface. This can be observed in the increased currents observed for the single dyes (Devices A1 and B1) but is even more apparent when more than one dye is present in the same photo-electrode (e.g. Device H3).

The processes of dyeing, desorption and re-dyeing in dye sensitized solar cells rely on the fact that dyes are chemisorbed onto the metal oxide $\left(\mathrm{TiO}_{2}\right)$ surface through ester linkages between dye carboxylate linker groups and surface hydroxyl groups of the metal oxide. The desorption step must therefore involve hydrolysis of the dye-surface ester bonds to release the dye molecules but without affecting either the dye or any of the other device components. Our evidence is that this can best be controlled through a combination of controlled alkalinity $\left(\mathrm{OH}^{-}\right)$ and a suitable counter-ion $\left(\mathrm{Bu}_{4} \mathrm{~N}^{+}\right.$or $\left.\mathrm{Li}^{+}\right)$. Hence these data show that it is possible to achieve completely selective dye desorption for N719 by using $\mathrm{LiOH}_{(\mathrm{aq})}$. A further advantage of using $\mathrm{Bu}_{4} \mathrm{NOH}$ or $\mathrm{LiOH}$ as the base for desorption is that, after dye desorption, the $\mathrm{Bu}_{4} \mathrm{~N}^{+}$salt of the dye is formed which can be re-used to dye other photo-electrodes.

The step-wise co-sensitization and selective desorption of N719 and SQ1 have also been studied by first dyeing a photoelectrode with N719 (1 ml, $2.5 \mathrm{mM})$ giving Device I1 with $\eta=$ $5.8 \%$ (Table 5). After electrolyte removal and rinsing, SQ1 (300 $\mu \mathrm{l}, 0.28 \mathrm{mM}$ ) was added was added to the N719-dyed electrode giving Device I2 with lower efficiency $(5.1 \%)$ mainly due to $J_{\mathrm{sc}}$ decreasing from $10.77 \mathrm{~mA} \mathrm{~cm}{ }^{-2}$ to $9.25 \mathrm{~mA} \mathrm{~cm}^{-2}$. Whilst the reason for the drop in $J_{\mathrm{sc}}$ is not entirely clear, it could be that no additional sorption sites are available as was the case for the partially desorbed Device F3 so the additional SQ1 may have aggregated with the N719 possibly causing some quenching of 
its excited state. N719 was then selectively desorbed by LiOH (50 $\mu \mathrm{l}, 100 \mathrm{mM}$ ) giving Device I3 where $\eta$ had dropped to $0.65 \%$ which was due to only a small SQ1 loading remaining. The UVvis spectrum for desorbed N719 by LiOH (see ESI $\dagger$ ) gives two peaks at $504 \mathrm{~nm}$ and $364 \mathrm{~nm}$ corresponding to $63.7 \mu \mathrm{g}$ N719 $\mathrm{cm}^{-2}$ and no evidence for SQ1 desorption. SQ1 was then desorbed using $\left(\mathrm{Bu}_{4} \mathrm{NOH} 100 \mu \mathrm{l}, 4 \mathrm{mM}\right)$. The resulting UV-vis spectrum shows only SQ1 corresponding to a loading of $11.8 \mu \mathrm{g}$ $\mathrm{SQ} 1 \mathrm{~cm}^{-2}$. After re-dyeing with SQ1 $(300 \mu \mathrm{l}, 0.28 \mathrm{mM})$, Device I4 gave $\eta=2.1 \%$ which increased to $5.2 \%$ when $1 \mathrm{ml}$ of $\mathrm{N} 719$ (2.8 $\mathrm{mM}$ ) was added (Device I5).

A similar experiment was carried out for N719 and D149 but using partial and selective desorption (Table 5). Thus, Device J1 was initially dyed with $1 \mathrm{ml}$ of $1 \mathrm{mM} \mathrm{N719} \mathrm{giving} \eta$ of $5.1 \%$ followed by partial N719 desorption using $\mathrm{Bu}_{4} \mathrm{NOH}(50 \mu \mathrm{l}, 4$ $\mathrm{mM}$ ) giving Device $\mathrm{J} 2$ with $\eta=3.6 \%$ and $J_{\mathrm{sc}}$ dropping to 10.16 $\mathrm{mA} \mathrm{cm}{ }^{-2}$ in line with the reduced N719 loading (UV-vis spectroscopy confirmed removal of $\left.116 \mu \mathrm{g} \mathrm{N} 719 \mathrm{~cm}^{-2}\right)$. D149 (250 $\mu \mathrm{l}$, $0.5 \mathrm{mM}$ ) was then added (Device J3) slightly increasing $\eta$ to $3.8 \%$ and $J_{\text {sc }}$ to $11.82 \mathrm{~mA} \mathrm{~cm}{ }^{-2}$. However, $V_{\text {oc }}$ dropped to $0.65 \mathrm{~V}$ because D149 gives lower $V_{\text {oc }}$ than N719. Following this, $106 \mu \mathrm{g}$ $\mathrm{N} 719 \mathrm{~cm}^{-2}$ was selectively and completely desorbed by a larger volume of LiOH $(200 \mu \mathrm{l}, 100 \mathrm{mM})$ giving Device J4 which, as expected, lowered $\eta$ to $2.9 \%, J_{\text {sc }}$ to $8.28 \mathrm{~mA} \mathrm{~cm}^{-2}$ and $V_{\text {oc }}$ to $0.60 \mathrm{~V}$. The remaining D149 loading $\left(22 \mu \mathrm{g} \mathrm{D} 149 \mathrm{~cm}^{-2}\right)$ was then
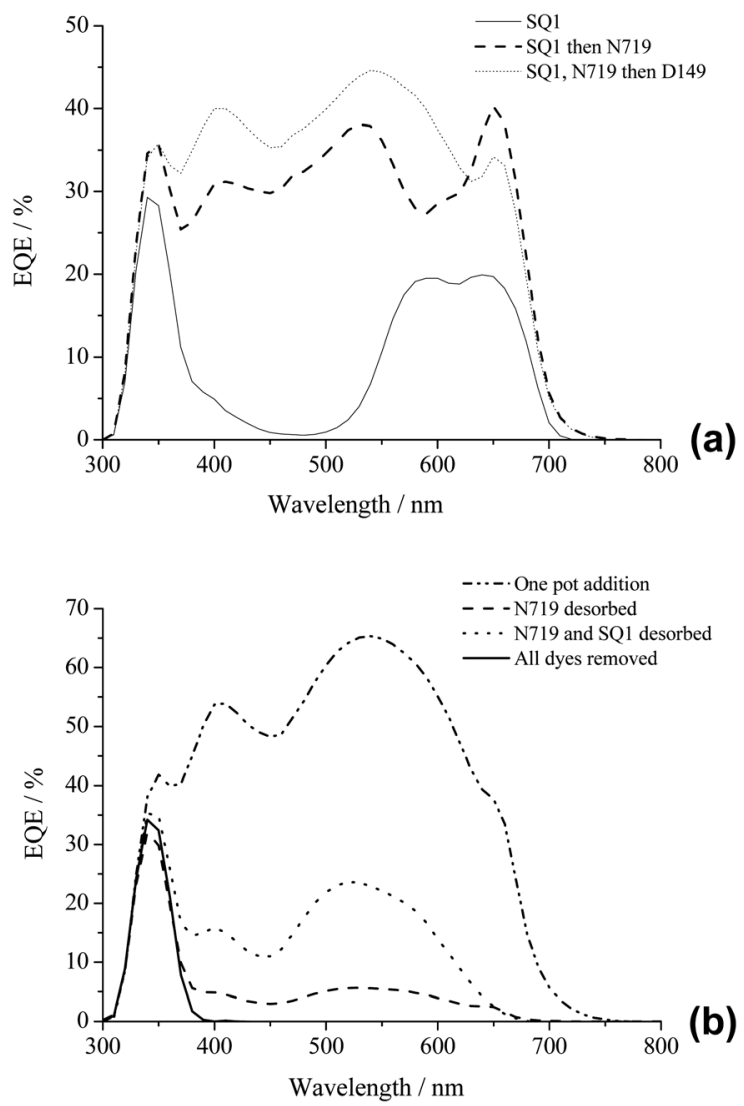

Fig. 4 EQE data for (a) DSC device dyed with SQ1, then N719, then D149 and (b) DSC device dyed with N719 + SQ1 + D149 mixture and then step-wise selective desorption of N719, then SQ1, then D149. desorbed by $\mathrm{Bu}_{4} \mathrm{NOH}(300 \mu \mathrm{l}, 40 \mathrm{mM})$ followed by $0.5 \mathrm{ml}$ acetone. After washing and rinsing, the device re-dyeing with N719 ( $1 \mathrm{ml}, 1 \mathrm{mM})$, Device J5, and the $\eta$ increased to $5.9 \%$ which may due the activation of $\mathrm{TiO}_{2}$ surface leading to form a monolayer of adsorbed dye molecules.

Sequential dyeing and desorption was then studied using SQ1, N719 and D149. First Device K1 was dyed with SQ1 (300 $\mu$ l, $0.28 \mathrm{mM}$ ) giving $\eta 2.3 \%$ which increased to $4.8 \%$ after $500 \mu \mathrm{l}$ of 1 mM N719 was added giving Device K2 and 5.5\% after $200 \mu \mathrm{l}$ of $0.5 \mathrm{mM}$ D149 was added giving Device K3. The $J_{\mathrm{sc}}$ increased in line with the addition of each dye in turn (Table 5). N719 was then selectively removed using LiOH $(100 \mu \mathrm{l}, 100 \mathrm{mM})$ giving Device K4 with $\eta$ dropping to $0.8 \%$ and $J_{\mathrm{sc}}$ to $1.44 \mathrm{~mA} \mathrm{~cm}^{-2}$ suggesting that N719 was the dominant light harvesting dye in this device. UV-vis spectroscopy (ESI Fig. S12 $\dagger$ ) confirmed selective N719 removal by LiOH and a loading of $132.5 \mu \mathrm{g}$ N719 $\mathrm{cm}^{-2}$ (Fig. 5). Next, SQ1 was selectively desorbed by $\mathrm{Bu}_{4} \mathrm{NOH}$ $(100 \mu \mathrm{l}, 1 \mathrm{mM})$ giving Device K5. This actually increased $\eta$ to $1.3 \%$ with slightly increased $J_{\mathrm{sc}}\left(3.7 \mathrm{~mA} \mathrm{~cm} \mathrm{~cm}^{-2}\right)$. The reason for this increase is not clear but presumably reflects the changing nature of the $\mathrm{TiO}_{2}$ surface with only D149 molecules adsorbed along with vacant sorption sites. UV-vis spectroscopy again confirmed selective SQ1 removal (Fig. 5) and a loading of $1.2 \mu \mathrm{g}$

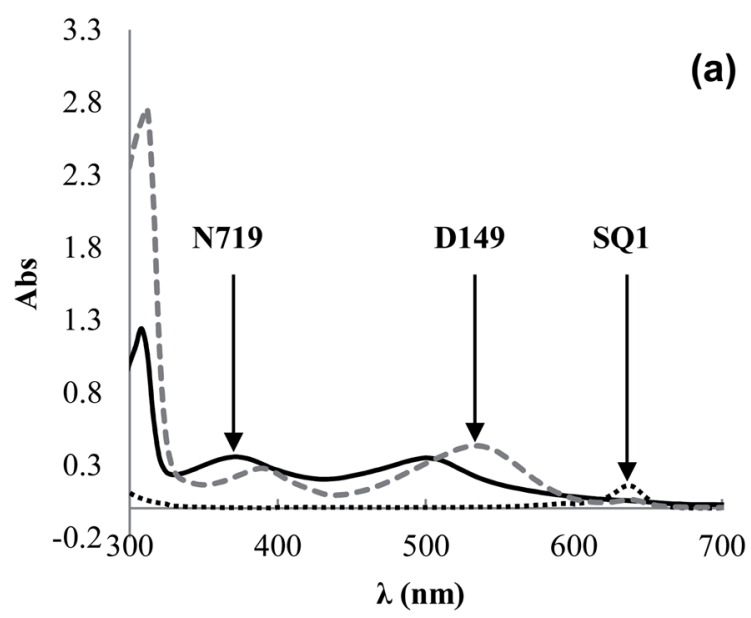

Selective dye removal

(b)
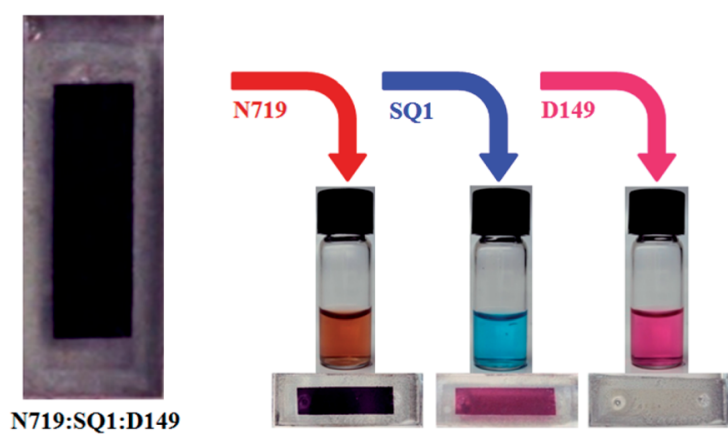

Fig. 5 (a) UV-visible spectra of desorbed dyes and (b) photographs of co-sensitized DSC and the same device after step-wise, selective desorption of N719, SQ1 and D149. 
SQ1 $\mathrm{cm}^{-2}$. Finally, D149 was desorbed by $\mathrm{Bu}_{4} \mathrm{NOH}(100 \mu \mathrm{l}$, $40 \mathrm{mM}$ ) followed by $200 \mu \mathrm{l}$ acetone and $100 \mu \mathrm{l}$ ethanol. UV-vis spectroscopy confirmed that only D149 was desorbed giving a loading of $3.9 \mu \mathrm{g}$ D149 $\mathrm{cm}^{-2}$. EQE of the tri-sensitized device showed responses for SQ1 at $660 \mathrm{~nm}$ and D149/N719 at ca. $550 \mathrm{~nm}$ (Fig. 4). The EQE for Device K4 containing SQ1 and D149 is significantly reduced after selective removed N719. The increase after selective SQ1 removal is in line with the $I-V$ data discussed above (Device K5). Fig. 5 shows photographs of a trisensitized device showing a dark brown coloration followed the by the same device after selective desorption of each dye also showing the desorbed dye solutions showing the red-brown N719, the blue SQ1 and the pink D149.

\section{Conclusions}

To make dye-sensitized solar cells more efficient, it is essential to significantly extend spectral response as far as possible from 400 to $700 \mathrm{~nm}$. In practice, this means extending out into the longer wavelength region whilst maintaining the spectral response from 450 to $700 \mathrm{~nm}$ which is where the most efficient devices reported to date operate. To achieve this whilst maintaining a consistently high spectral response at all wavelengths is most likely to require the use of multiple dyes along with very close control of dye loadings and most probably dye positioning as well. Our data show that dye desorption and re-dyeing offers great control of all these parameters whilst also suggesting that it is potential to reduce the amount of dye used within a photoelectrode with relatively less effect on device performance with obvious benefits for reducing cost. The method can also be easily adapted for very rapid, high throughput testing of multiple dyes using a single device as we have repeated multiple dyeing-desorption-dyeing cycles through the same device cavities without any loss of device performance. In the context of the long-term stability of DSC devices, these data may also provide a warning about the use of electrolyte components such as tertiary-butyl pyridine which may have the potential to desorb dye in the presence of water if this is able to enter the device over extended weathering periods.

\section{Acknowledgements}

We gratefully acknowledge Iraqi Govt. support for KJA, ERDFWG LCRI funding for SPARC (AC, EWJ and MLD), EPSRC SPECIFIC funding (MLD) and NSG for supply of TEC ${ }^{\mathrm{TM}}$ glass to the SPARC consortium.

\section{Notes and references}

1 B. O'Regan and M. Grätzel, Nature, 1991, 353, 737.

2 A. Hagfeldt, G. Boschloo, L. Sun, L. Kloo and H. Pettersson, Chem. Rev., 2010, 110, 6595.
3 A. Yella, H.-W. Lee, H. N. Tsao, C. Yi, A. K. Chandiran, M. K. Nazeeruddin, E. W.-G. Diau, C.-Y. Yeh, S. M. Zakeeruddin and M. Grätzel, Science, 2011, 334, 629.

4 M. K. Nazeeruddin, P. Péchy and M. Grätzel, Chem. Commun., 1997, 1705.

5 S. Pack, H. Choi, C. Kim, N. Cho, S. So, K. Song, M. K. Nazeeruddin and J. Ko, Chem. Commun., 2011, 47, 2874.

6 J. N. Clifford, E. Palomares, M. K. Nazeeruddin, R. Thampi, M. Grätzel and J. R. Durrant, J. Am. Chem. Soc., 2004, 126, 5670.

7 H. Choi, S. Kim, S. O. Kang, J. Ko, M.-S. Kang, J. N. Clifford, A. Forneli, E. Palomares, M. K. Nazeeruddin and M. Grätzel, Angew. Chem., Int. Ed., 2008, 47, 8259.

8 F. Inakazu, Y. Noma, Y. Ogomi and S. Hayase, Appl. Phys. Lett., 2008, 93, 093304.

9 R. Y. Ogura, S. Nakane, M. Morooka, M. Orihashi, Y. Suzuki and K. Noda, Appl. Phys. Lett., 2009, 94, 073308.

10 K. Lee, S. W. Park, M. J. Ko, K. Kim and N. Park, Nat. Mater., 2009, 8, 665.

11 J.-J. Cid, J.-H. Yum, S.-R. Jang, M. K. Nazeeruddin, E. Martinez-Ferrero, E. Palomares, J. Ko, M. Grätzel and T. Torres, Angew. Chem., Int. Ed., 2007, 46, 8358.

12 D. Kuang, P. Walter, F. Nüesch, S. Kim, J. Ko, P. Comte, S. K. Zakeeruddin, M. K. Nazeeruddin and M. Grätzel, Langmuir, 2007, 23, 10906.

13 J. N. Clifford, A. Forneli, H. Chen, T. Torres, S. Tan and E. Palomares, J. Mater. Chem., 2011, 21, 1693.

14 C.-M. Lan, H.-P. Wu, T.-Y. Pan, C.-W. Chang, W.-S. Chao, C.-T. Chen, C.-L. Wang, C.-Y. Lin and E. W.-G. Diau, Energy Environ. Sci., 2012, 5, 6460.

15 L. H. Nguyen, H. K. Mulmudi, D. Sabba, S. A. Kulkarni, S. K. Batabyal, K. Nonomura, M. Grätzel and S. G. Mhaisalkar, Phys. Chem. Chem. Phys., 2012, 14, 16182.

16 P. J. Holliman, M. L. Davies, A. Connell, B. V. Velasco and T. M. Watson, Chem. Commun., 2010, 46, 7256.

17 P. J. Holliman, M. Mohsen, A. Connell, M. L. Davies, K. AlSalihi, M. B. Pitak, G. J. Tizzard, S. J. Coles, R. W. Harrington, W. Clegg, C. Serpa, O. H. Fontes, C. Charbonneau and M. J. Carnie, J. Mater. Chem., 2012, 22, 13318.

18 S. W. Park, K. Lee, D.-W. Lee, M. J. Ko, N.-G. Park and K. Kim, Nanotechnology, 2011, 22, 045201.

19 B. O'Regan, L. Xiaoe and T. Ghaddar, Energy Environ. Sci., 2011, 5, 7203.

20 P. J. Holliman, N. Ahmed and M. Davies, unpublished work. 21 J. H. Yum, P. Walker, S. Huber, D. Rentsch, T. Geigar, F. Nuesch, F. de Angelis and M. Grätzel, J. Am. Chem. Soc., 2007, 129, 10320.

22 P. Wang, C. Klein, R. Humphrey-Baker, S. M. Zakeeruddin and M. Grätzel, J. Am. Chem. Soc., 2005, 127, 808. 